\title{
A MEDICINA POPULAR NA OBRA DE ALVARO CUNQUEIRO
}

José M. a Eiros Bouza

Universidad de Valladolid

doi:10.17075/mucnoc.2014.052 

Forcadela, M. / T. López / D. Vilavedra (coords.) (2014): Mil e un cunqueiros. Novas olladas para un centenario, Santiago de Compostela, Consello da Cultura Galega. doi:10.17075/mucnoc.2014. pp. 967-978

\section{LIMIAR}

A presente comunicación ten como base só o atrevemento a expoñer unhas breves cavilacións como lector afervoado da obra de Álvaro Cunqueiro. A nosa actividade profesional dentro da medicina non é a máis axeitada para permitir un achegamento do estudo a estas cuestións. Só o feito de nacer e medrar nesta terra que nos acolle, fíxome acadalas dun xeito case que imperceptible.

No desenvolvemento do tema, seguiremos un esquema fundamentado en seis apartados. Primeiro, situaremos a medicina popular no contexto da obra de Álvaro Cunqueiro. Segundo, falaremos das súas fontes de coñecemento e desenvolvemento. Nos apartados tres, catro e cinco, referirémonos á tipoloxía do menciñeiro de Cunqueiro. No terceiro, veremos o xeito de aproximarse ao doente e ao menciñeiro. No cuarto, comentaremos a capacidade do mencińeiro para comprender o feito da enfermidade e a súa especialización. No quinto, presentaremos os seus métodos de tratamento e poderes de trasmundo. En sexto lugar, para rematar, falaremos doutros saberes e dos casos clínicos.

\section{A MEDICINA POPULAR NA OBRA DE ÁLVARO CUNQUEIRO}

Escola de menciñeiros, Xente de aqui e de acolá e Os outros feirantes constitúen una fermosa triloxía protagonizada por figuras populares do país. Son tres libros de Cunqueiro que conteñen historias nas que fala maiormente de xentes que coñeceu.

Se ben o tema da medicina popular no conxunto da obra de Cunqueiro excede esta triloxía, nosoutros imos referirnos á tipoloxía dos menciñeiros que recolle na súa Escola...: Perrón de Braña, Borrallo de Lagoa, Xil da Ribeira, Lamas Vello, o Coxo de Entrebo, Pardo das Pontes, Silva da Posta, o Señor Cordal, Cabo de Lonxe e o Licho de Vilamor. Cómpre sinalar que o propio Álvaro engade a estes dez a Mel de Vincios, tal como advirte en Xente de aqui e acolá: 
«Cando escribín a miña Escola de menciñeiros quedáronse esquencidos Mel de Vincios, Pita de San Cobade e un discípulo de Mel, un tal Lousas que non sei se vive ou morreu». Destes dous últimos só deixou esta referencia.

A pesar de canto se leva falado sobre da medicina popular, hai un feito do que convén decatarse: o tratamento que dela fai Cunqueiro é absolutamente xenial. Para afondar nel, mesmo lixeiramente, cómpre situalo no contexto da súa obra e considerar o que el cavilaba inquedo sobre os seus personaxes: a súa galeguidade, o seu maxín, as súas dúbidas...

Seguindo a súa propia expresión, convén lembrar a carta que Álvaro lle escribía a García Sabell (eminente médico-psiquiatra e destacada figura da cultura galega) hai corenta anos para consultarlle a identidade dos seus escritos: «Eu terqueio — di Cunqueiro- que istes son retratos de xentes da nosa tribu, e que poderían ser de outra calisquer. Querse decir que hai neles unha onza en cadaquén do ser galego, e repartido entre toda esta xentińa están as súas varas de medir o mundo, as voltas do seu maxín, as reviravoltas dos seus sońos e devozos, a súa calidade intelectual». E máis adiante sinala: «Ten o galego un xeito de imaxinar que lle é propio». O cumio da inquietude que lle orixinaba a súa propia obra exprésao ao fin deste xeito: «Eu non poido profundar no choio, que non son antropólogo nin xiquer folklorista comparatista, nin nada centífico. Son un que anda entre istes nosos e conta. Eu quero saber si hai moita diferencia entre o vivo e o pintado, ou mais craro ainda: si istes de meu son ou non son galegos, e que é o que predican do galego». Fondamente significativas son as verbas seguintes, nas que segue a dicir Cunqueiro: «[...] e entón eu, nas miñas dúbidas, remato perguntándome — perguntándoche— si houbo ou hai, ou non, un Álvaro Cunqueiro». E para finalizar prégalle: «Cando teñas algo que vagar contéstame, que xa te decatarás que ando algo preocupado con iste asunto».

Estas reflexións, que foron escritas cando Cunqueiro ordenaba Xente de aqui e de acolá, poden aplicarse tamén a Escola de menciñeiros, xa que, como queda dito, manteñen unha mesma lińa estilística.

Xustamente é García Sabell quen define a Escola... como unha solución de compromiso entre o pulo da fantasía e o tirón da realidade. Cunqueiro escribiu estes relatos co criterio que sempre sostivo, coa mesma fidelidade á terra e ao home, á lingua e á tradición, mesturando maxistralmente unha insólita comprensión do 
ser do noso país, que tanto o preocupaba — como xa expomos—-, e uns envexables dotes de observación.

\section{FONTES DE CONEECEMENTO E DESENVOLVEMENTO}

A primeira fonte de contacto de Álvaro coa farmacoloxía e a botánica ten orixe na súa nenez.

De seu pai, don Joaquín Cunqueiro, que era farmacéutico, coméntalle el mesmo a Carlos Casares: «O meu pai era un bon boticario e un bon zoólogo, sobre todo un grande botánico. Amigo do campo, cazador e pescador, moitas tardes, cunha escopeta do vinteoito dobrada debaixo da zamarra, saímos de paseo. Ensinábame todo e aprendín deseguida. Eu sabía tódalas herbas do mundo: a festuca pantesis, a daptila numenta, os trevos, os lirios.., en fin, todas herbas había por alí.»

Este coñecemento directo da natureza, sen dúbida alentado polas explicacións de seu pai, verase completado, segundo as declaracións na devandita entrevista, polo feito de axudar na botica: «[...] gustábame moito. En primeiro lugar, eu sabía de memoria todos os botes cos seus nomes estraños. Preguntábame qué habería dentro do bote que decía maná ou no que puña opio. Sabía a pirafidona, o sulfito de fontán e toda clase de preparados. Axudáballe ao meu pai a facer as píldoras e os selos na máquina, a remexer nos xaropes, a darlle ao muińo da mostaza para os sinapismo. Todas aquelas cousas que se elaboraban naquel entón.»

A botica é tamén a fonte de contacto con parte dos mencińeiros que van encher os seus relatos. Aínda que haxa quen cre que todos eses personaxes son froito da imaxinación, algúns existiron. Na biografía sobre Álvaro que publicou hai poucos anos, Armesto comenta os testemuños de Pepe Cunqueiro (irmán do Álvaro) de como ten atendido na botica do seu pai a algúns deles. En Escola... refire en catro contos esta circunstancia. De Perrón de Braña di sinxelamente: «Viña moito pola botica de meu pai». De Borrallo de Lagoa escribe: «Eu parece que o estou vendo na botica de meu pai, agardando a que lle despachasen pastillas de clorato i un peso do augardente alemán». En Cabo de Lonxe, refire: «Na botica de meu pai mercaba nitrato de plata para queimar as verrugas». En Pardo das Pontes, sinala dobremente este feito: «Viña a botrica do meu pai, sentábase nun recuncho, botaba un pito, e nin tiña ganas de apostas coa letra nin de falar de Cuba». E máis adiante volve 
lembralo situándose cronoloxicamente na súa vida: «Cando eu era nen, e viña Pardo á botica nosa, eu sempre lle andaba pedindo que asubiase, e Pardo, facéndose de rogar, imitaba para min o melro, a rula, i o paxaro que en Cuba chaman, en Camagüey, guaro tentador».

Engade forza á realidade deste trato directo cos menciñeiros a propia afirmación de Álvaro na cabeceira do libro: «Xente é ista da que falo que conocín, i alguna de mui perto».

Non cala, por iso, a orixe e lugar de nacemento da maioría deles, todos das nosas Terras de Miranda. Xil da Ribeira, natural de Ribeira de Piquín; Lamas Vello de Santalla de Oscos, paisano de Mel de Vincios; O Coxo de Entrebo, da parroquia de Labrado de Buriz, no municipio de Vilalba; Silva da Posta era de Reigosa, na Pastoriza; O Señor Coral, da Serra da Corda, que enxergamos desde a nosa cidade de Mondoñedo, e O Licho de Vilamor viña sendo do devandito concello.

Ademais, no senso de fidelidades aos seus personaxes, Álvaro describe maxistralmente o seu cariz e tipoloxía. Vaian como exemplos este dous: «Perrón [refírese a Perrón de Braña] era de mediana talla, entrerroibo, os ollos craros, mui lucida de ouro a dentadura. Gastaba gorra visera negra e vestía de pana», "Cabo de Lonxe era de mediana estatura, gordo e colorado, os ollos mouros e vivos, unha grande boca sempre aberta, que falaba a berros e seguido. Tiña, en troques, unhas mans finas, mui ditosas de movementos cando loubaba i amosaba unha sortixa ou un rosario».

Así pois, as fontes de cońecemento para o desenvolvemento dos seus realtos teñen orixe na súa nenez: seu pai, a botica e os tipos da súa contorna nas Terras de Miranda.

\section{O DOENTE E O MENCIŃEIRO}

Convén lembrar neste apartado o que os especialistas no tema consideran sobre do que son o doente e o curandeiro.

O doente que acode a un curandeiro non propón un conxunto de síntomas para que sexan ordenados en enfermidades, o que propón é una situación vital enigmática, unha adiviña existencial para que sexa descifrada. E os síntomas son unha parte da adiviña, tal e como expón García Sabell, que engade: «nas boas, un curandeiro galego é un home de prima doutrińa, humorista si cadra, psicólogo sempre, que 
cree, de boa fé, arrecadar poderes persoales dabondo para sandar ós seus semellantes [...] Os mencińeiros están respaldados por modo inconscente na cultura herdada. I entón intuien con acuidade que ningún doente se cura de verdade si non se conquire centralo na vida, situalo no mundo cotidián, chantado ben chantado na leira da eisistencia que lle corresponda- Eles adiviñan que sandar é una obriga difícil, porque é una empresa total, cousa de raigańas profundas, de relaciós esenciaes, de suma e definitiva comunicación, de solidaridade coa vida».

No caso que nos ocupa, os mencińeiros cunqueiráns entenden o doente como un todo, corpo e alma. Non só abranguen o motivo da consulta, senón que transcenden e esculcan a totalidade da persoa. Adoptan unha actitude aberta para o home en desvalemento que teñen ao seu carón. Álvaro recolle maxistralmente este aspecto cando escribe de Lamas Vello: «Tiña, como tódolos curadores que eu cońecín, unha postura de amigable escoitar, de garimoso confesor». Deste xeito de escoitar é tamén Perrón de Braña: «estaba unha hora cumprida cabo do doente, fumando, falando de cousas de ir e vir, do tempo que corría e mais da xente allea». Outras veces, o encontro é aínda máis prolongado, como no caso de Borrallo de Lagoa, quen «levaba ó Listeiro (paciente del) tódalas seráns a pasear, paseos de dúas ou tres leguas, e como quizaves se faría noite na volta, quedaban a durmir nunha pousada ou nun palleiro».

Queda, pois, documentado o feito de aproximarse e cońecerse entre o doente e o menciñeiro que propón Cunqueiro: falar e pasear, que oxalá! fose adoptado pola nosa banda en medicina.

\section{A CAPACIDADE DO MENCIŃEIRO}

Quizais o expoñente máis atractivo que da concepción de enfermidade ten Cunqueiro é o que conta de Lamas Vello: «A súa tesis era que as doencias adentrámolas en nós mesmos. Un sońo, poño por caso, pode dar unha doencia, o mesmo que unha anguria, un mal pensamento, un desexo insatisfeito, a envexa que lles temos a Fulán ou Mengán, a mala teima que pomos naqueloutro. Unha persoa humildosa, calada, amiga, esmoleira, está inmunizada contra moitas doencias. Os soberbios, avaros, chufós, irados, sobresaltan o sangue, i adoitan o corpo para que lles veña unha doencia». 
Aproveita este mesmo relato Cunqueiro para amosar con forza o feito de que "tódalas doencias teñen un nome humán, que os médicos non saben; os médicos sábenlles ás doencias en xeral un nome centífico, e por iso percisan dunha cencia para curar, con menciñas centíficas».

En contraposición, o curandeiro ten en conta a historia persoal do home en padecemento dende os seus devanceiros, a nenez, a mocidade, casamento, traballos e fraquezas.

O doente poderá ter nun intre, como di Alvaro, unha pedra ou dúas na illada, "pro ten ademais toda isa historia, á que hai que dar un nome humán, e soio cando se lle atopa ese nome humán, e soio cando se lle atopa ese nome humán á doencia [...] saberase si poderá curar ou non». Ao remate, Lamas Vello non pode ser mais concluínte: «Moitos hai, aseguraba, que non están doentes. E que se anoxan».

Outro xeito de concibir a enfermidade mais acorde coa medicina hipocrática é a teoría dos humores, que Pardo das Pontes troca en ventos: «Drento do corpo temos ventos: nordés, vendaval, xistral e foulas quentes, i o de dentro abanéase nunha ou noutra parte asegún o vento que esteña soprando».

No tocante á especialización dos menciñeiros, Cunqueiro sitúaos con competencia en doenzas moi diversas que van dende aquelas con fondo psicolóxico até as puramente somáticas, de fondo orgánico.

Non imos matizar estes conceptos, pero si lembrar os talentos mais nomeados de cada un dos personaxes. Borrallo de Lagoa atendía tolos, morriñosos e afrixoados, cunha clara orientación que chamamos neuropsiquiátrica. Tamén actuaban nestes lindeiros Silva da Posta, que sacaba a «sombra íspera» aos tolos e quitaba a morteira ademais de levantar a paleta e amparar os estómagos caídos. Mel de Voincios botaba pequenos demos dos corpos dalgunhas xentes. Unha preferencia por doenzas con mais compoñente orgánico (é dicir, con máis base somática) era a de Xil de Ribeira, que sabía moito de ventre e quitaba o que chaman «volverse o sudor», que é — di Cunqueiro- suor frío, tatabexar de dentes seguido, perder peso, marcharlle a un a cor.

Ao meu entender, é de singular e repousada beleza a descrición que fai Álvaro do que en medicina chamamos nós un «síndrome constitucional»: astenia, palidez, perda de peso, no seo dunha crise de aterecemento. É absolutamente xenial. Finalmente, actúan en lindeiros corporais e orgánicos Pardo das Pontes, gran compo- 
ñedor de ósos (no que tamén era apreciado Mel de Vincios), Cabo de Lonxe (que queimaba verrugas) e o Licho de Vilamor, que sacaba as moas sen dor.

\section{TRATAMENTO E PODERES DE TRASMUNDO}

A riqueza expresiva da obra de Cunqueiro ten unha forza tan viva de seu que unha interpretación popular como a que eu poida facer desdebúxaa imperdoablemente, por iso convén lembrar o que el asegura: «Dos curadores quén conto, sempre me solprendéu o que de feito curaran doentes». E, quizais por iso, mestura a arte de cada mencińeiro xunto cos métodos terapéuticos máis ou menos ortodoxos, pero con fundamento fisiopatolóxico e farmacoterápico (como son sangrías, sinapismos, purgantes, esencia de herbas, fregas e horas de sono), outra modalidade de tratamento que puidese considerarse dirixida á esencia vital do home (á súa intelixencia, aos seus afectos, á súa psique).

Algúns exemplos que ilustran esta dupla metodoloxía de curar son: Perrón de Brańa curaba con sangrías, papas de avea ou centeo, baños quentes e moitas horas de sono. Contáballe ao doente unha adiviña ben retorta e chea de cabos soltos, coa recomendación seguinte: «Cando veña a sangrarte, a ver si ma tés sacada». O interese dese procedemento queda remarcado por Cunqueiro cando di: «Os enfermos de Perrón devecían polas historias que contaba iste, comentábanas, parrafeábanas coa família, cos veciños, soñaban coelas. Poucas adiviñanzas eran acertadas».

Outro exemplo desta mestura de métodos de tratamento atopámolo en Borrallo de Lagoa, que purgaba forte e, deseguido, curaba tolos, morriñosos e afrixoados. E o primeiro que facía cun tolo era cambiarlle o nome e inventáballe unha vida nova. Parte da súa terapéutica consistía en aprender a ler.

En ocasións, no tratamento, destaca o réxime de comidas, tal e como facía Xil da Ribeira, que receitaba queixos vellos, xamón, viño doce, viño quente e baños. Xil ademais herborizaba con macela, xenciana e salgueiro.

Noutras veces, o tratamento era eminentemente vital e do que chaman agora «terapia ocupacional». Lamas Vello receitaba baños, vacacións e buscáballe pasatempos aos enfermos. A algúns curounos procurándolles matrimonio, a outros facéndoos rir con historias que el, un home tan serio, contaba moi ben. 
Velaí unha mostra da mestura de métodos terapéuticos que Álvaro pon no arsenal dos seus menciñeiros, aos que engade, como cómpre para destacar a súa autoridade, outros poderes especiais ou de trasmundo. Así, Perrón de Braña quitaba as verrugas de palabra e a varias légoas de distancia. A Borrallo de Lagoa deixábano só no campo ou na eira cos tolos irados e non lle facían nada; «obedecíano e quedábanse».

Silva da Posta era moi imaxinativo «en tratos con xentes do sobermundo que andiveran por istes pagos», e adiviñaba de quen era a crianza que tivera tal moza. O Coxo de Entrebo chegou a ter fama de mago, anunciaba as crianzas que traian as cochas, adiviñaba se un que estaba nas Américas vivía ou non, e del asegurábase que estivo ao mesmo tempo en lugares separados seis leguas. Do Señor Cordal, di Cunqueiro: "Como home intelixente i espiritual que era, Cordal era fondamente supersticioso, dado en atopar agoiros i en provocalos».

\section{OUTROS SABERES E CASOS CLÍNICOS}

Sen dúbida, Cunqueiro remata a faciana humana dos seus tipos cando lles atribúe outras competencias. Deste xeito, falaban o latín Cabo de Lonxe e o Coxo de Entrebo, do que di que aprendera latín co crego de Begonte e, nun ano, a Gramática de Araújo non tiña segredos para el.

Outros eran bos músicos, como Xil da Ribeira, que en solfexo non tiña punto, e Silva da Posta, do que comenta que se adicou a ir aos enterros co seu harmonio «de valija» e que lle saían unhas funcións moi solemnes. Pero o número de afeccións era moi grande. Xil da Ribeira era xastre de doentes, Pardo das Pontes xogador de lotaría. Tamén neste senso destaca Álvaro a conexión dos seus menciñeiros coa natureza e coa veterinaria. O Señor Cordal era moi atento observador da natureza, sempre con gusto de saber o nome de cada herba, de cada flor, cantos e costumes dos paxaros. Todo, segundo el, pendía da lúa. Para el como para un grego, un sacrificio reiteradamente cumprido é necesariamente eficaz, porque hai unha orde universal, e as varias partes do cosmos respéctanse mutuamente e concordan. Do Coxo de Entrebo sinalaba que «tomóu forma como albéitar. As doencias do cabalar non tiñan segredos para íl». 
Ten interese o feito de que moitos saberes que Cunqueiro incorpora aos seus menciñeiros foron aprendidos nas súas viaxes. Ou ben no servizo militar [Xil da Ribeira] ou en Madrid [O Coxo de Entrebo], ou moitos máis en América, basicamente en Cuba [como Pardo das Pontes] ou Arxentina [casos de Silva da Posta e o Señor Cordal].

Un aspecto innovador e atractivo de Cunqueiro é o feito de que engade casos clínicos e testemuños de doentes curados polos mencińeiros. Borrallo de Lagoa, do que xa sabemos que curaba afrixoados, comenta o caso dun tal Listeiro, «que se deixaba morrer e nas serodias fixérase blasfemo». A este díxolle Borrallo: «AAínda me has de levar no colo ao San Cosme de Galgao!» O Listeiro soltou a palabra e xurou que non chegaría a tal festa, que a vida era unha merda, dispensando, e el un cabrito, e que non se colgaba para non darlle no gusto a unha nora que tińa. Borrallo acompañouno en longos paseos durante algún tempo e polo camiño ensinábao a ler. «Chegóu o 27 de setembro do 1914, i o Listeiro entrou no campo da Xesta, onde é a Romería do San Cosme de Galgao, levando no colo ó Borrallo, ben enzarramado, que acolá enriba sempre sopran nordestes».

Do mesmo Borralo sinalaba: «Valía máis que Conxo!, díxome un moi amigo del. De neno afixo a comer no mesmo zatico de pan a un rato e a un merlo. Tiña moi estudada á xente».

En Lamas Vello, do que xa dixemos que a súa tese era que as doenzas as interiorizamos nós mesmos, ilustramos o caso seguinte: «Arún que lle chamaban o Folgo de Vilameá, i era prestamista, púxoselle un sudor alternado que non o deixaba: cando ardía, cando morrían, cando brixía de frío. Cando tiña frío, tremaba tanto que nin podía facer o conta dos intereses. Non durmía, asustado. Os médicos non lle acertaban, e gastou mais de cen pesos nas boticas de Ribadeo. Non era mais que pel e osos. Os sobriños chamaron a Lamas vello. Lamas pechouse co doente toda unha serán. - Tí o que tés é ansia e nada mais. Deixa todo, viste a roupa mais vella e vaite a marińa, $\mathrm{i}$ andas por alí dous ou tres meses agora que vén o bó tempo a pedir esmola. Non leves contigo nin un perrochico. Fai que non conoces. Ti pides mui humilde, das a gracias, bicas a esmola e nada mais, e — prosegue CunqueiroO Folgo fixo o recetado e curou, curou do corpo e millorou da ialma. Os que lle debían cartos atopábano máis comprensivo. Chegóu os noventa».

Velaí dous casos clínicos cuxa precisión e beleza seguro que nos moven a gozar lendo a devandita Escola de menciñeiros. 
